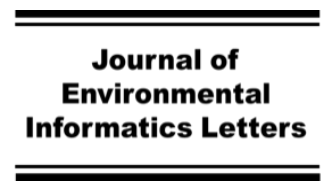

www.iseis.org/jeil

\title{
Response of Surface Water Quality in Urban and Non-urban Areas to Heavy Rainfall: Implications for the Impacts of Climate Change
}

\author{
Q. $\mathrm{Wu}^{1}$, and X. H. Xia ${ }^{1 *}$ \\ ${ }^{1}$ School of Environment, Beijing Normal University-State Key Laboratory of Water Environment Simulation, Beijing 100875, China
}

Received 13 December 2018; revised 23 February 2019; accepted 25 February 2019; published online 31 March 2019

\begin{abstract}
Frequency and intensity of floods and droughts are increased across the world due to global climate change. However, the responses of water quality in urban and non-urban areas to extreme weather events are not well understood. The heavy and extensive precipitation during the summer of 2011 and 2012 caused two severe floods in Beijing of China. This work evaluated the impacts of these two floods on the water quality of 10 urban lakes, 3 non-urban reservoirs, and 8 non-urban rivers through comparing the pre-flood and post-flood water quality as well as those in reference period $(2006 \sim 2010)$. Results indicated that the lagging response of water quality to flood is more significant in non-urban areas than the urban areas. In addition, comprehensive pollutant index (CPI) during the first flood period in most sites were much higher than the reference values with the average increasing rate of $46 \%$. The values of chemical and biological oxygen demand were elevated in most sites; total nitrogen in the non-urban areas and total phosphorous in the urban areas were higher than those in the reference period. The different responses of nitrogen and phosphorus to the flood events of the two areas were mainly due to the high nitrogen contents in non-urban soils and high phosphorus contents in the urban soils. Whereas, most pollutant concentrations during the second flood period were lower than the first flood period, or even lower than the reference period. This can be explained by that the first flood, belonging to the post-drought flood, scoured the land surface and brought plenty of pollutants into the aquatic environments, and the non-point source pollution caused by the second flood was less effective and mainly reflected as dilution effect. This study suggests that the response of surface water quality to floods caused by climate change will differ between urban and non-urban areas, as well as among different flood events.
\end{abstract}

Keywords: heavy rainfall, water quality, urban area, non-urban area, flood risk management

\section{Introduction}

Climate change refers to the variations in distribution of meteorological factors (i.e., temperature, precipitation, wind velocity, and radiation), which is also associated with extreme weather events (Stott et al., 2016; Ummenhofer and Meehl, 2017). Future climate is predicted to have an increasing frequency, intensity, and duration of extreme weather-related water events such as floods and droughts (Beniston, 2012; Cann et al., 2013; Mosley, 2015; Xia et al., 2015a). The changes in frequencies and magnitudes of extreme water events might further affect the water quality and aquatic ecosystem by altering the hydraulic residence time and migration/transformation of pollutants (Dotto et al., 2010, 2012; Hubbard et al., 2011; Beaver et al., 2013; Mccarthy et al., 2014; Delpla and Rodriguez, 2014; Xia et al., 2015a; Fink et al., 2016). For instance, Hrdinka et al. (2012) studied the impacts of the flood and drought on the water quality in central Bohemia, Czech Republic, and found that both flood and drought significantly deteriorate the water quality, and the impact of flood was se-

${ }^{*}$ Corresponding author. Tel.: + (86) 10-58805314;

E-mail address: xiaxh@bnu.edu.cn (X. H. Xia).

ISSN: 2663-6859 print/2663-6867 online

(C) 2019 ISEIS All rights reserved. doi:10.3808/jeil.201900004 verer. In addition, the post-drought flood could also result in more serious water quality problems by flushing more pollutants previously accumulated in the surface soils to the water environment. Whitworth et al. (2012) reported that the postdrought floods in southern Murray-Darling Basin, Australia scoured large quantities of dissolved organic carbon stored in the soils into the water, depleting the dissolved oxygen and caused the severe hypoxic black water event. In general, floods can lead to the inundation and erosion of surface area that change the redox-oxidizing environment. And heavy rainfall can easily cause the diffusion pollution and a redistribution of pollutants between contaminated sediments and uncontaminated water (Wu et al., 2014a, b). Droughts can affect the water quality and aquatic ecosystem through concentrating the pollutants (VanVliet and Zwolsman, 2008), or reducing the water level, further leading to the exposure of pollutants and changing biogeochemical processes (Aherne et al., 2006).

Streams, reservoirs, and lakes, acting as the receiving water of non-point source pollution, their response to floods might be different between urban and non-urban areas due to the different land use types, pollution sources, and hydrological conditions (Wang et al., 2008; Madarang et al., 2014; Vincent and Kirkwood, 2014; Ramachandran et al., 2018). For instance, results of our previous study showed that the mean total phos- 
phorus (TP) contents in urban soils were $112 \mathrm{mg} \cdot \mathrm{kg}^{-1}$ higher than those in rural soils of Beijing; meanwhile, the mean total nitrogen (TN) contents in rural soils were 2.6-fold higher than those in urban soils (Xia et al., 2013). In addition, the imperviousness of the urban areas due to rapid urbanization would enhance partitioning of rainfall into runoff, leading to higher runoff ratios and longer runoff duration than those in the non-urban areas (Gallo, 2011). Therefore, we hypothesize that there exist different responses of water quality in urban and non-urban areas to extreme weather events due to their different hydrological conditions and pollutant concentrations.

So far, most studies on the impacts of floods on water environment mainly focus on observing the changes in water flow or assessing the flood induced diffuse pollution by hydrological models (Yang et al., 2011). The impact of heavy rainfall on water quality in urban and non-urban areas is still unknown and need be studied and compared. Here we studied the impact of two heavy storms occurred in 2011 and 2012 on water quality in 21 sampling sites from non-urban reservoirs/rivers and urban lakes in Beijing, China. We analyzed the changes of preflood and post-flood water quality. We also compared the water quality during the two extreme flood periods and the reference periods (2006 2010 for non-urban area and $2009 \sim 2010$ for urban areas). The analyzed water quality parameters include the chemical oxygen demand $\left(\mathrm{COD}_{\mathrm{cr}}\right)$, biological oxygen demand (BOD), dissolved oxygen (DO), TN, and TP. The influencing mechanism and factors of flood on different water types were identified and compared.

\section{Materials and Methods}

\subsection{Study Sites}

Beijing $\left(39^{\circ} 28^{\prime} \mathrm{N} \sim 41^{\circ} 05^{\prime} \mathrm{N}, 115^{\circ} 25^{\prime} \mathrm{E} \sim 117^{\circ} 30^{\prime} \mathrm{E}\right)$, the political and economic center of China, is located in the Haihe River Basin with semi-humid continental climate and four distinct seasons. Annual precipitation is between $470 \sim 500 \mathrm{~mm}$ with uneven temporal and spatial rainfall distribution. General characteristics and locations of the studied lakes, reservoirs, and rivers are shown in Table $\mathrm{S} 1$. The studied non-urban reservoirs and rivers as well as urban lakes sites are shown in Figure 1. The studied non-urban reservoirs and rivers are located in Miyun Reservoir catchment (Figure 1), where water quality is less affected by human activities and can well reflect the influence of variations in meteorological factors; the major land use types are agricultural lands, barren lands, orchards, and forests. Relative high nitrogen and soil organic matter concentrations in non-urban soils have been reported (Xia et al., 2013; Heimann et al., 2015). These reservoirs and rivers are located in the upstream of the Miyun Reservoir watershed; they are shallow waters, flowing through the farmland and forestry land, then into the Miyun Reservoir. The metropolitan area of Beijing covers $1,381 \mathrm{~km}^{2}$ with a population of 12.8 million people. The main land use types of the urban area are residential and commercial lands as well as recreational parks. High phosphorus concentrations in urban soils have been reported (Xia et al., 2013). As discussed in our previous study (Wu et al., 2014a, b), most urban lakes in Beijing are artificial and shallow lakes, locating in the recreational parks with similar land use/scope.

\subsection{Extreme Water Events}

After a decade-long drought period, Beijing experienced two intense rainfalls, which caused severe floods in the whole city including urban and non-urban areas. The first flood occurred on June $23^{\text {rd }}$ of 2011 with average daily precipitation of $96 \mathrm{~mm}$. The second flood occurred on July $21^{\text {st }}$ and $22^{\text {nd }}$ of 2012 with parts of the region received $519 \mathrm{~mm}$ of precipitation, which was the heaviest storm and flood disaster during the past 60 years in Beijing. It lasted for 19 hours with the characteristics of short time, strong intensity, and large rainfall. During the flood period (June to September) of 2012, the accumulated precipitation reached $532 \mathrm{~mm}$, accounting for $75 \%$ of the total annual precipitation, and the precipitation is $11 \%$ higher than the value of $497 \mathrm{~mm}$ during the same period of 2011 (Figures 2 and S1).

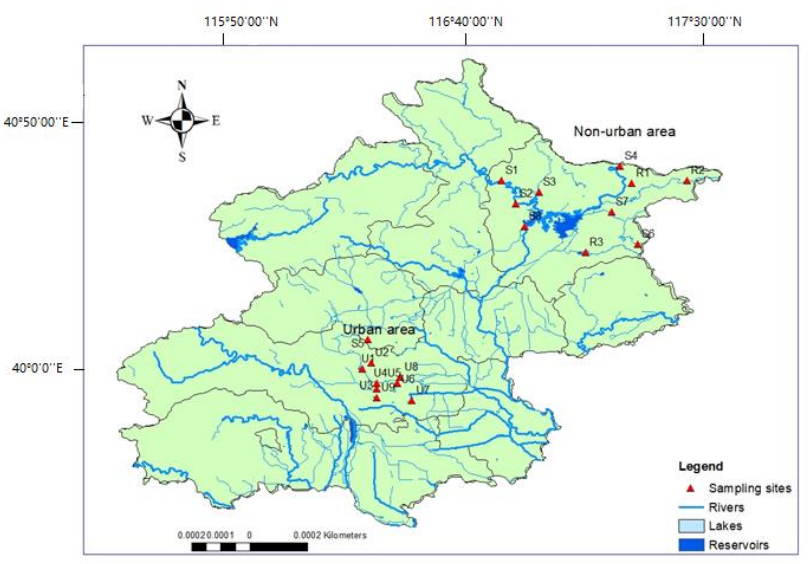

Figure 1. Sampling sites of non-urbanand urban watersin Beijing. (R1 Banchengzi Reservoir; R2 Yaoqiaoyu Reservoir; R3 Shachang Reservoir; S1 Sihetangqiao Station; S2 Daguanqiao Station; S3 Baimaguan Station; S4 Gubeikou Station; S5 Xinzhuangqiao Station; S6 Qiangzilu Station; S7 Putaoyuanqiao Station; S8 Baihe main dam; U1 Lake Kunming; U2 Lake Fuhai; U3 Lake Yuyuantan; U4 Lake Zizhuyuan; U5 Lake Houhai; U6 Lake Qianhai; U7 Lake Longtan; U8 Lake Qingnian; U9 Lake Lianhua; U10 Lake Liuyin).

\subsection{Water Quality Sampling and Analysis}

The water sampling was carried out monthly except for the frozen period (mainly from January to March) from 2006 to 2012 for non-urban area and from 2009 to 2012 for urban area. The detailed measurements of Secchi depth, water temperature, $\mathrm{pH}$, dissolved oxygen (DO), COD, BOD, TN, and TP of the water samples can be found in our previous study (Wu et al., 2014a; Xia et al., 2015b). Monthly stream discharges were collected from the online Water Resource Yearbook of the Haihe River Basin (http://www.hwcc.gov.cn/hwcc/wwgj/xxgb/ szygb/). Meteorological data including monthly mean air temperature, cumulative precipitation, and maximum precipitation in Beijing were collected from the online China Meteorological 
Data Sharing Service System (http://data.cma.cn/data).

We averaged the monthly value of each parameter from 2006 to 2012 except the flood season (June to September) as the reference values in non-urban areas. Due to the limited data in urban area, we took the same period with non-urban areas from 2009 to 2012 as the reference in urban regions. We choose the water quality in the non-flood seasons because we did not know how floods would affect the water quality during the flood season, adding these values could interrupt the comparison. We firstly compared the pre-flood and post-flood water quality. Then we compared the water quality in the same flood month with those in different years. In addition, we compared the water quality during the flood month in 2011 and 2012 with the reference values.

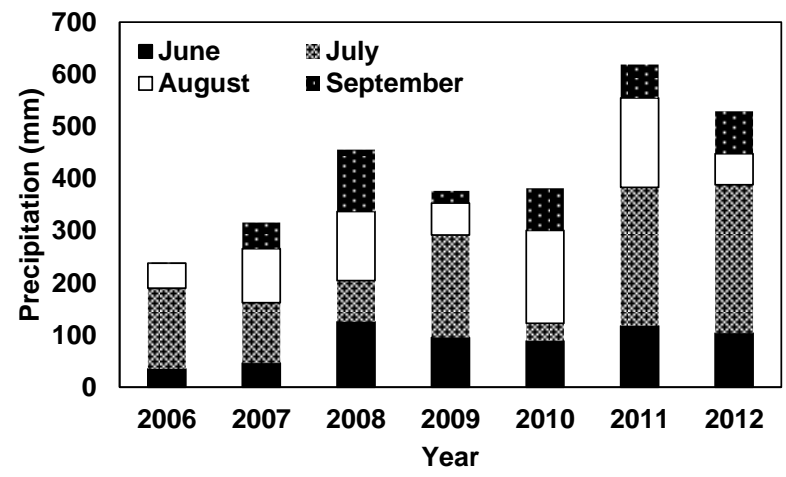

Figure 2. Precipitation of wet season in Beijing during the period of $2006 \sim 2012$.

\subsection{Statistical and Assessment Method}

Here we applied the comprehensive pollution index (CPI) to assess the water quality. Calculation of each water quality parameter is shown as follows:

$P_{i}=\frac{M_{i}}{S_{i}}$

where $P_{i}$ is the individual index of water quality parameter $i$, $M_{i}$ is the measured concentration of $i\left(\mathrm{mg} \cdot \mathrm{L}^{-1}\right) ; S_{i}$ is the concentration of stipulated standard of pollutant $i\left(\mathrm{mg} \cdot \mathrm{L}^{-1}\right)$; here we took the Class III standard of national classification of pollutants for surface water, which is the basic standard for second protection zone of centralized drinking water source, detailed information is shown in Table S2. If $P_{i}>1$, concentration of pollutant $i$ has exceed the stipulated standard. According to the reported high nutrient and organic matter contents in soil and water of Beijing (Xia et al., 2013; Yuan et al., 2016), we took parameters including COD, BOD, TN, TP, and DO into the CPI equation. Detailed calculation is shown as follows:

$C P I=P_{C O D}+P_{B O D}+P_{T N}+P_{T P}-P_{D O}$

We used the same CPI assessment standard from previous study of Liu et al. (2011); the water quality is classified as ex- cellent when CPI $<0$; water quality is good when $0 \leq \mathrm{CPI}<1$, water is beginning to be contaminated when $1<\mathrm{CPI}<2$, water body is lightly polluted, moderately polluted, and heavily polluted when $2<\mathrm{CPI}<3,3<\mathrm{CPI}<4$, CPI $>4$, respectively.

All data were tested for normality and homogeneity of variance. Pollutant concentrations measured during the flood period were compared with the corresponding mean concentrations in the reference period. Statistical significance tests of these differences in different periods and regions were examined using ANOVA test. All the statistical analysis was performed with Microsoft Excel 2007 (Microsoft Inc., USA) and IBM SPSS Version 19.0 (SPSS Inc., Chicago, IL, USA).

\section{Results and Discussions}

\subsection{Characteristics of Water Quality during the Reference Years}

We found significant differences $(p<0.05)$ in COD, BOD, TP and CPI values in urban and non-urban areas during the reference years (Table S3). Meanwhile high nutrient concentrations of the urban lakes were observed. Average TP and TN concentrations during the reference period (non-flood season from $2006 \sim 2012$ ) in the urban waters were 0.07 and 3.10 $\mathrm{mg} \cdot \mathrm{L}^{-1}$, respectively, which were approximately 3 -fold and 1.5 fold higher than those in the non-urban waters during the reference period (Tables 1 and 2). Contents of oxygen-consuming organic pollutants in urban lakes were also higher than those in the non-urban waters. For instance, average values of both COD and BOD of urban lakes during the reference years were 30.43 and $6.32 \mathrm{mg} \cdot \mathrm{L}^{-1}$, respectively, which were more than 6 times higher than those of non-urban waters (Tables 1 and 2). In the non-urban areas, water quality related with COD and BOD were better than those in the reservoirs. The difference could be explained by the good fluidity of rivers, which means short water residence time and strong dilution effect for oxygen-consuming organic pollutants.

CPI values of R1, R2, and R3 (i.e., Reservoir Banchengzi, Yaoqiaoyu, and Shachang) in reference years were 1.1, 0.8, and 1.2 , respectively (Table 1). Meanwhile, the CPI values of most non-urban rivers were in the state of excellent water quality (A $<0)$ (Table 1). For all the urban lakes, CPI of U1 (Lake Kunming) during the reference period was the lowest with value of 0.13, then was U4 (Lake Zizhuyuan, 0.58) and U2 (Fuhai, 0.93), indicating that water quality of the three urban lakes were good (Table 1). However, CPI values of the other urban lakes ranged from 1.47 to 7.79 , which showed that water quality of these urban lakes were being or been polluted. U7 (Lake Longtan) exhibited the highest CPI value of 7.79, and was three times higher than the contemporary average values of urban lakes (Figure $3)$.

As shown in Figure 3, average CPI values of non-urban areas (A1) was 3-time less compared with average CPI values of urban areas (A2), indicating surface water quality in non-urban area was better than that in urban area. This is mainly because Miyun Reservoir Watershed (the non-urban area) belongs to the drinking water area with little point source pollu- 
Table 1. The Average Water Quality and Comprehensive Pollution Index (CPI) in Non-urban Area

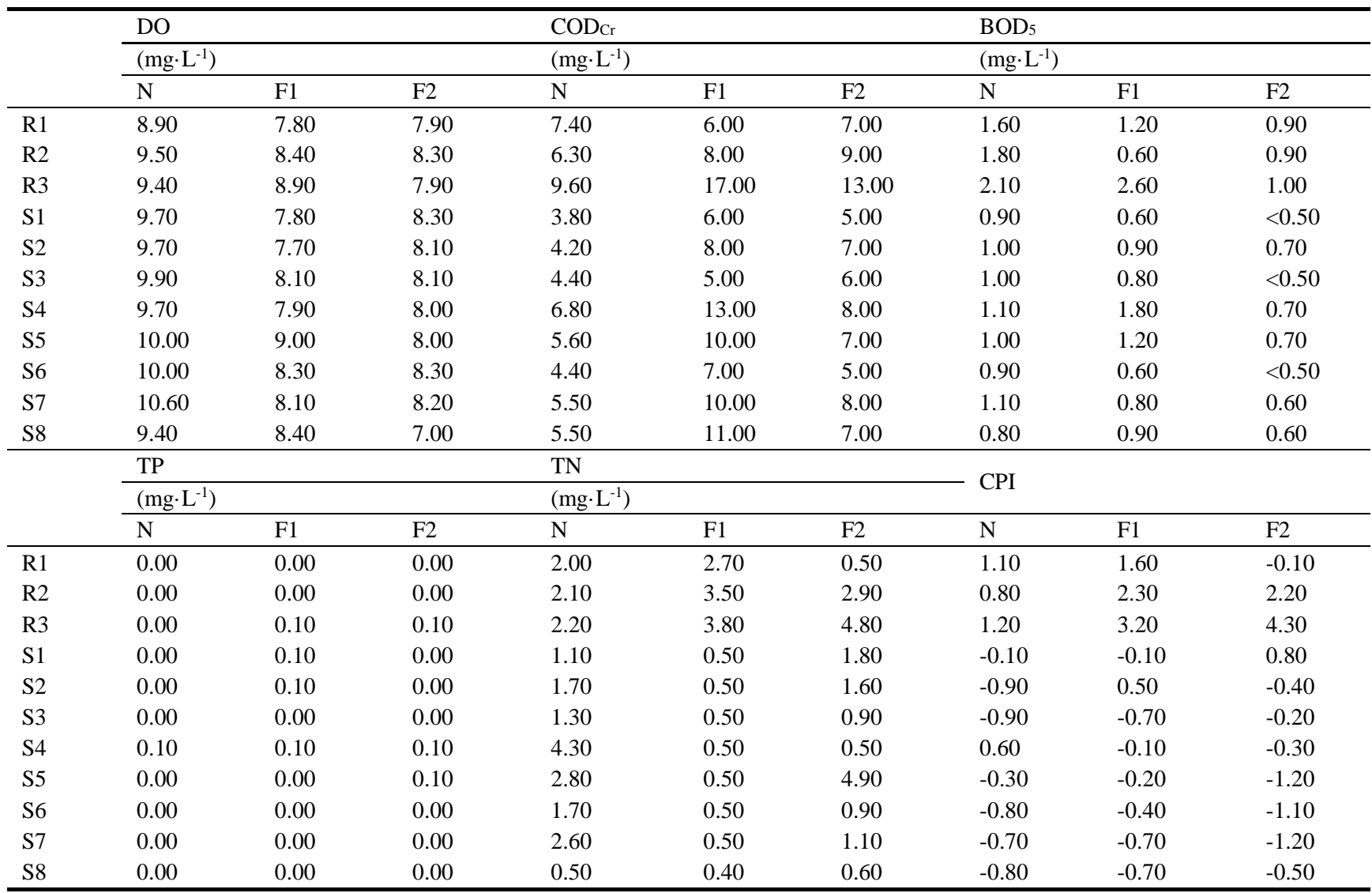

*"N" indicates the reference period (2006-2010), and "F1"and "F2" indicate the flood occurred in 2011 and 2012, respectively.

tion (Xia et al., 2015). Whereas, urban water quality is vulnerable due to the large population density, sewerage discharge and diffusion pollution.

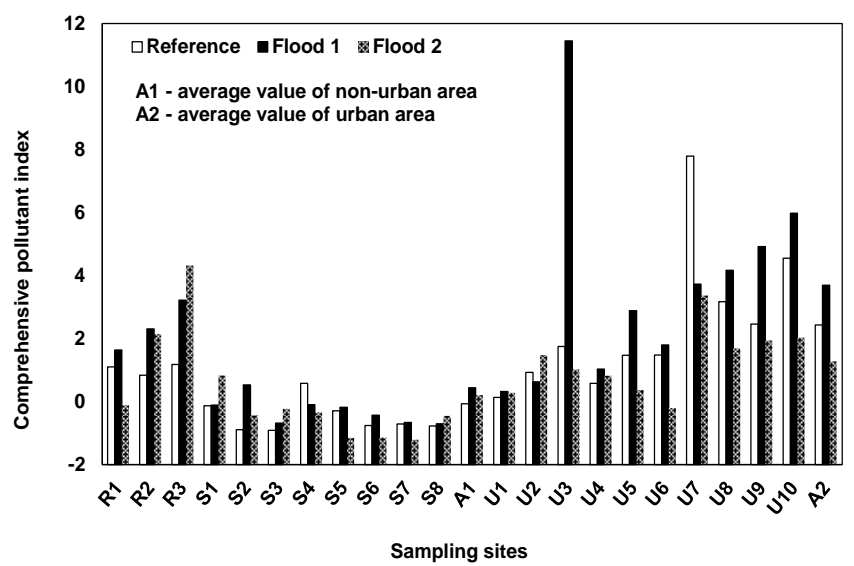

Figure 3. Comprehensive pollution index (CPI) in non-urban and urban area of Beijing.

\subsection{Impact of the First Flood Event on the Water Quality of Non-urban Reservoirs and Rivers}

We compared the pre-flood and post-flood water quality by comparing the water quality parameters within the flood period (from June to September). For the first flood happened in the late-June 2011, we can find the decreased DO concentration and increased COD, BOD, and TN values right after the flood month in the urban lakes. However, this trend of water quality parameters was more significantly in the following months (especially in August and September) in non-urban areas. The increased post-flood pollutants could be contributed by the nonpoint source pollution and the sediment resuspension. The lagging responses of water quality to the flood event in the nonurban areas is probably caused by responding time of storms to surface runoff; these phenomena have also been reported in other studies (Walling and Foster, 1975; Hamilton, 2012; Chen et al., 2014; Change et al., 2015; Putro et al., 2016). The lag effect of pollutant transportation is caused by hydrologic conditions and biogeochemical processes (Van Meter et al., 2017; Chen et al., 2019). The lag time can range from a few hours to decades (Walling and Foster, 1975; Li et al., 2011; Hamilton, 2012; Hu et al., 2018). In most hydrological models in catchment, the surface runoff lag coefficient is set as 24 days (Chen et al., 2019; Liu et al., 2016). In addition, studies of Gao et al. (2012) also reported one-month delay of peak phosphorus concentrations in southwest China. These results are consistent 
Table 2. The Average Water Quality and Comprehensive Pollution Index (CPI) in Urban Area

\begin{tabular}{|c|c|c|c|c|c|c|c|c|c|}
\hline \multirow{3}{*}{ Number } & \multicolumn{3}{|l|}{ DO } & \multicolumn{3}{|l|}{$\mathrm{COD}_{\mathrm{Cr}}$} & \multicolumn{3}{|c|}{$\mathrm{BOD}_{5}$} \\
\hline & \multicolumn{3}{|c|}{$\left(\mathrm{mg} \cdot \mathrm{L}^{-1}\right)$} & \multicolumn{3}{|c|}{$\left(\mathrm{mg} \cdot \mathrm{L}^{-1}\right)$} & \multicolumn{3}{|c|}{$\left(\mathrm{mg} \cdot \mathrm{L}^{-1}\right)$} \\
\hline & $\mathrm{N}$ & F 1 & $\mathrm{~F} 2$ & $\mathrm{~N}$ & $\mathrm{~F} 1$ & $\mathrm{~F} 2$ & $\mathrm{~N}$ & $\mathrm{~F} 1$ & $\mathrm{~F} 2$ \\
\hline U1 & 10.14 & 8.00 & 6.90 & 14.86 & 13.00 & 19.00 & 2.62 & 1.00 & 5.00 \\
\hline $\mathrm{U} 2$ & 10.23 & 6.60 & 11.90 & 22.66 & 37.00 & 39.00 & 3.44 & 3.00 & 9.00 \\
\hline U3 & 8.88 & 4.20 & 7.00 & 22.57 & 48.00 & 33.00 & 4.34 & 6.00 & 8.00 \\
\hline U4 & 8.45 & 5.60 & 5.80 & 21.00 & 26.00 & 16.00 & 3.67 & 3.00 & 2.00 \\
\hline U5 & 11.48 & 6.00 & 7.80 & 22.56 & 23.00 & 26.00 & 3.46 & 3.10 & 3.00 \\
\hline U6 & 11.88 & 6.80 & 10.10 & 22.56 & 22.00 & 18.00 & 3.62 & 3.50 & 3.40 \\
\hline U7 & 9.36 & 5.90 & 6.90 & 45.11 & 83.00 & 34.00 & 5.35 & 8.20 & 6.90 \\
\hline U8 & 10.02 & 8.10 & 8.10 & 35.80 & 27.00 & 37.00 & 5.04 & 9.00 & 8.00 \\
\hline U9 & 8.72 & 6.80 & 5.80 & 31.03 & 26.00 & 38.00 & 5.65 & 9.00 & 5.00 \\
\hline U10 & 7.54 & 8.90 & 7.60 & 66.13 & 102.00 & 62.00 & 26.03 & 57.70 & 21.80 \\
\hline \multirow{3}{*}{ Number } & $\mathrm{TP}$ & & & $\mathrm{TN}$ & & & \multirow{2}{*}{\multicolumn{3}{|c|}{ CPI }} \\
\hline & \multicolumn{3}{|c|}{$\left(\mathrm{mg} \cdot \mathrm{L}^{-1}\right)$} & \multicolumn{3}{|c|}{$\left(\mathrm{mg} \cdot \mathrm{L}^{-1}\right)$} & & & \\
\hline & $\mathrm{N}$ & $\mathrm{F} 1$ & F 2 & $\mathrm{~N}$ & $\mathrm{~F} 1$ & $\mathrm{~F} 2$ & $\mathrm{~N}$ & $\mathrm{~F} 1$ & $\mathrm{~F} 2$ \\
\hline U1 & 0.05 & 0.07 & 0.02 & 1.33 & 1.29 & 0.66 & 0.13 & 0.32 & 0.28 \\
\hline $\mathrm{U} 2$ & 0.04 & 0.06 & 0.02 & 1.85 & 1.07 & 2.83 & 0.93 & 0.63 & 1.47 \\
\hline U3 & 0.07 & 0.26 & 0.05 & 2.77 & 9.76 & 1.09 & 1.75 & 11.45 & 1.02 \\
\hline U4 & 0.06 & 0.07 & 0.02 & 1.38 & 1.13 & 0.98 & 0.58 & 1.03 & 0.82 \\
\hline U5 & 0.04 & 0.07 & 0.06 & 2.79 & 3.04 & 1.06 & 1.47 & 2.89 & 0.37 \\
\hline U6 & 0.04 & 0.03 & 0.02 & 2.83 & 2.14 & 0.90 & 1.48 & 1.80 & -0.20 \\
\hline U7 & 0.07 & 0.19 & 0.09 & 7.94 & 1.99 & 2.53 & 7.79 & 3.73 & 3.37 \\
\hline U8 & 0.10 & 0.18 & 0.09 & 3.57 & 3.60 & 1.08 & 3.17 & 4.17 & 1.69 \\
\hline U9 & 0.08 & 0.08 & 0.12 & 2.78 & 5.00 & 1.62 & 2.46 & 4.92 & 1.94 \\
\hline U10 & 0.13 & 0.23 & 0.04 & 3.44 & 4.34 & 2.45 & 4.55 & 5.98 & 2.03 \\
\hline
\end{tabular}

*"N" indicates the reference period (2009-2010), "F1"and "F2" indicate the flood occurred in 2011 and 2012, respectively

with our observation that the lagged time of pollutant leaching from non-urban soils to waters in Beijing is about 1 month.

Different from non-urban areas, the altered land cover caused by rapid urbanization tends to reduce the lag response by fast partitioning of rainfall into runoff. A study of Kjeldsen et al. (2013) also observed the reduced lag time in the urban areas during flood events in the United Kingdom. In addition, TP concentrations were stable after the flood in most non-urban sites, whereas, elevated in the urban lakes. This is probably due to the low phosphorus concentrations in the non-urban soils and high concentrations in the urban soils, further suggesting the main influencing approach of first flood on water quality is by non-point source pollution.

Despite the lagging effect, high CPI values in three nonurban reservoirs of June 2011 and July 2012 were observed (Figure S2). As shown in Figure S2, in most non-urban reservoirs, COD values were lower and TN concentrations were higher during the two flood months than those during the same months in other years. This might be explained by the dilution effect for oxygen-consuming organic pollutants and high nitrogen non-point source pollution. Meanwhile, TP concentration did not exhibit consistent change during the flood month. Divergent variations in water quality parameters of non-urban rivers were observed (Figure S3).

Considering the lag effect of the storm water on water quality, we put an emphasis on analyzing the variations in water quality during the flood season. Compared with the reference years, water quality during the first flood season had a large degree of variability. We found significantly $(p<0.05)$ different DO and TP concentrations compared with the reference period (Table S4). In addition, we can find high COD values in nonurban reservoirs and rivers. For instance, COD value of R3 (Reservoir Shachang) during the first flood season was approximately 2 times higher than the reference years (Figure 4). Meanwhile decreased DO concentration was observed during the first flood season (Figure 4). The strong surface runoff probably flushed plenty of labile carbon into the surface water, decomposition of organic matter cost DO concentrations and increased the COD values. Contrary to COD, BOD in eight of the eleven non-urban reservoirs and rivers was lower during the first flood period than the value in reference period (Figure 4). This could be explained by that BOD reflects the contents of easily degrading organic pollutants, which mainly come from domestic sewage and not influenced by precipitation induced diffuse pollution. Meanwhile, the large water discharge during the flood period can make low values of BOD by dilution effect. However, BOD in R3 (Shachang Reservoir), S4 (Gubeikou Station), and S5 (Xinzhuangqiao Station) were higher than other sites, which might be caused by the relative high contents of easy degrading organic pollutant around these sampling sites. 

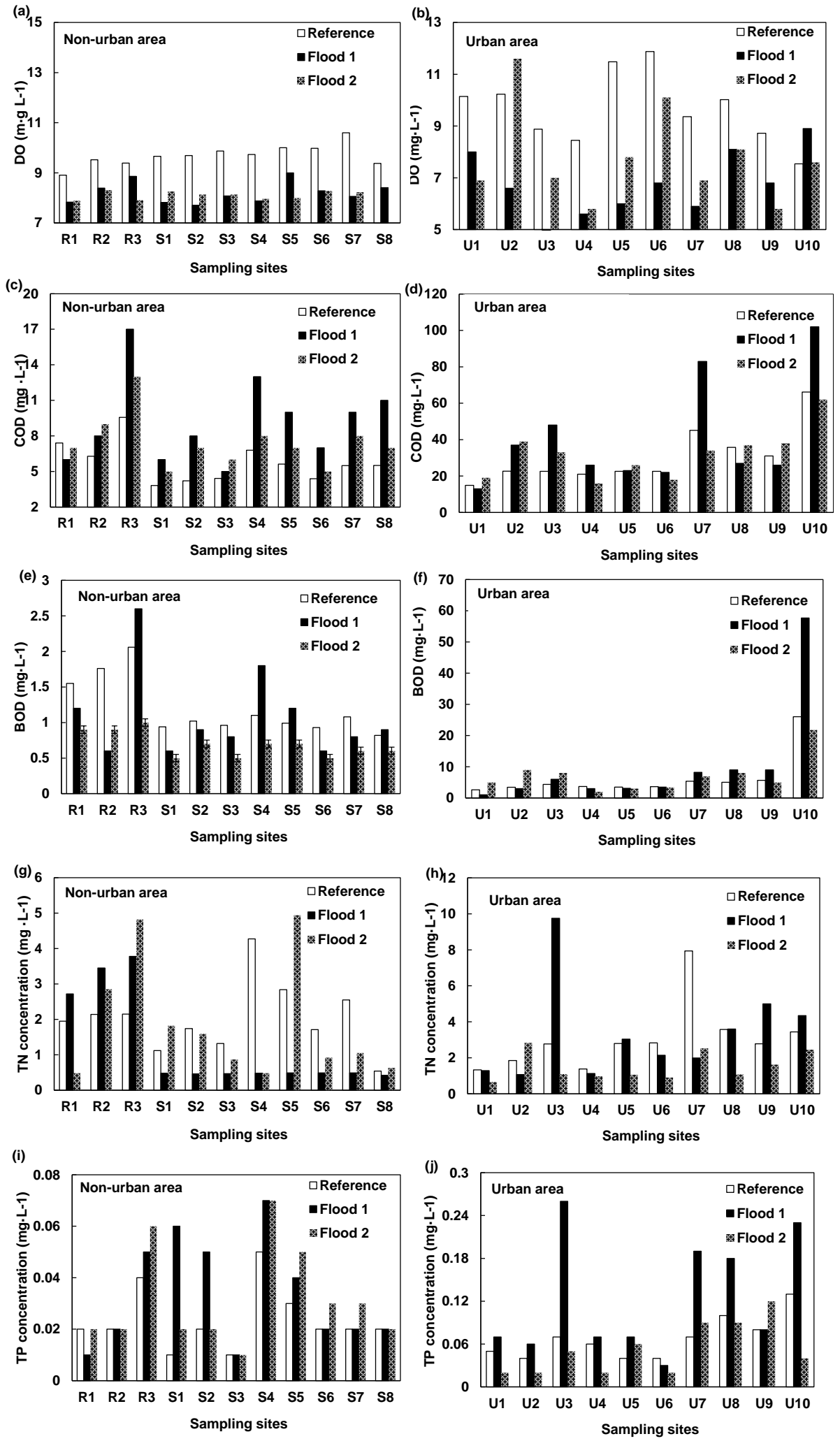

Figure 4. Water quality parameters including (a) DO in non-urban sites, (b) DO in urban sites, (c) COD in non-urban sites, (d) COD urban sites, (e) BOD in non-urban sites, (f) BOD in urban sites, (g) TN in non-urban sites, (h) TN in urban sites, (i) TP in non-urban sites, and (j) TP in urban sites during the reference, first flood, and second flood period, respectively. 
TN concentrations of the non-urban reservoirs and one half of the rivers were much higher during the first flood period than those during the reference period (Figure 4). The high TN concentrations in the non-urban reservoirs are mainly caused by the high nitrogen stored in the soils. While due to the high flowability of non-urban rivers during the flood period, they probably lead to low TN concentrations in the other non-urban river sites. During the flood, high flow rates increased the river mixing depth and further affected the pollutant distribution. Therefore, the water quality of non-urban rivers during the flood season is strongly influenced by hydrodynamic characteristics such as water residence time and physicochemical conditions. Contrast with TN, TP concentration did not show significant variation trend during the first flood season. In addition, CPI also showed higher values during the first flood period (Figure 3), indicating that the integrated water quality of nonurban water was not good.

\subsection{Impact of the First Flood Event on Water Quality of Urban Lakes}

As mentioned above, we found the quick response of urban waters to the first flood by comparing the pre-flood and post-flood water quality. In addition, through comparing with the water quality of urban lakes in the same flood month of different years, COD values in five of the ten urban lakes were higher in June of 2011, and other water quality parameters exhibited inconsistent variations (Figure S4). Despite of the different variations of individual water quality parameters, the CPI values of most lakes exhibited high values during the first flood month (Figure S4).

By enlarging the time scale, similar changing trend of water quality with non-urban waters during the first flood season was observed. DO in urban lakes also showed lower concentration; COD values of most urban lakes were significantly higher than those during the reference period (Figure 4). For instance, COD values of U3 (Lake Yuyuantan) during the first flood period were 2 times higher than those during the reference years. Average COD values of urban waters were $30.4 \mathrm{mg} \cdot \mathrm{L}^{-1}$ higher than those of non-urban waters during the first flood period, indicating more oxygen-consuming organic pollutants were flushed into the urban waters. Leónet al. (2015) also found the significantly increased organic contaminant concentrations in Mediterranean coastal lagoon (Spain) during the flood events because of the strong flush of surface soils. Compared with the reference periods, there was no consistent variation in BOD values during the first flood period. The divergent changes of water quality parameters in urban lakes were probably as a consequence of the presence of many simultaneous sources. Likewise, Launay et al. (2013) also reported that the different temporal variations of organic pollutants in the receiving water bodies of River Schwippe, Germany were caused by their different origins (i.e., waste water, urban runoff, or roof runoff, and so on)

Contrary to the nutrients in non-urban reservoirs, higher TP concentrations and lower TN concentrations in most urban lakes were observed during the first flood event, indicating dif- ferent influences of flood event on TP and TN. In our results the differences mainly represented as enhanced diffusion pollution impact for phosphorus and dilution effect for nitrogen. Combined with the variations in nutrient concentration of nonurban area and our previous studies (Xia et al., 2013; Wu et al., 2014a), the difference could be attributed to the higher phosphorus contents in the urban soils than that in the non-urban soils as well as the higher nitrogen content in the non-urban soils than those in the urban soils. The different responses also indicate that the surface water quality is mainly controlled by the heavy rainfall induced non-point source pollution. Besides, various underlying surface conditions of urban and non-urban areas may contribute to the different changes in water quality. For example, Delpla and Rodriguez (2014) studied the changes in water quality with different climate and land use scenarios, and their results demonstrated that variations in land use types could lead to changes in turbidity and fecal coliforms in the aquatic environment.

Overall, the first heavy rainfall events deteriorated the water quality; CPI values in most study sites were much higher than the reference period with the average increasing rate of $46 \%$. According to our previous studies on the impact of meteorological variations on water quality of urban lakes, despite of the impact of heavy rainfall event, precipitation/temperature together explained the $11 \sim 37.4 \%$ of the variations in COD and $11 \sim 47.9 \%$ of the variations in TP during the period from 2009 to 2011 (Wu et al., 2014a). Thus, the impact of heavy rainfall and high temperature on water quality should have a higher impact than the above values. However, different from our studies, Liu et al. (2011) assessed the sea water quality of Hebei Province in Bohai Sea, China; their results showed that water quality of rivers in Haihe River watershed during the flood period was better than that in the dry season; organic pollution index was $1.5 \sim 40$ times lower in the flood season compared with the dry season. The decreased pollution was mainly due to the increased water level and enhanced dilution effect of the rivers inflowing to the Bohai Sea. Unlike the inland rivers, the complex hydrodynamic conditions of the estuary could account for the differences. In conclusion, changes of water quality during the floods are related to the heavy rainfall runoff. Pollutant concentrations in the water can either decrease with the increased flow discharge or increase with more pollutants carried by flood runoff. For most surface waters in North China, non-point source pollution and dilution effect of heavy rainfall coexist and interact. Which one has a stronger impact is highly relied on the contamination level of the water and soils around the receiving waters and the hydrodynamic conditions.

\subsection{Impact of the Second Flood Event on Water Quality of Non-urban and Urban Areas}

For the second flood happened in July of 2012, it is interesting to find increase in DO and nutrient concentrations in the post-flood month; meanwhile COD and BOD values decreased or did not change in most studied urban lakes after the flood. For instance, the monthly $\mathrm{TN}$ and $\mathrm{TP}$ concentrations in U2 (Lake Fuhai) decreased from 3.23 and $0.07 \mathrm{mg} \cdot \mathrm{L}^{-1}$ before the 
flood to 2.83 and $0.02 \mathrm{mg} \cdot \mathrm{L}^{-1}$ after the flood, respectively. There are no consistent variations between pre-flood and postflood water quality in non-urban sites.

Similar response of COD and BOD during the second flood period with the first flood period were observed. For instance, COD values of S3 (Reservoir Shachang) during the second flood period were approximately 1.5 times higher than the reference season (Figure 4). BOD values in most study sites were lower compared with the reference periods (Figure 4). During the second flood season, TN in most of the non-urban and urban waters and TP in urban lakes were lower compared with the reference period (Figure 4). However, relative high TP concentrations during the second flood period were observed in half of the non-urban sites; the phosphorus in the aquatic environment was probably released from sediments due to strong intensity of the second flood.

Response of water quality to the two flood periods was different. For instance, CPI, COD, and BOD values in most surface water during the first flood were much higher compared with the second floods (Figures 3 and 4). Taking S4 (Gubeikou Station) as an example, COD during the first flood period was 13 $\mathrm{mg} \cdot \mathrm{L}^{-1}$, which was $5 \mathrm{mg} \cdot \mathrm{L}^{-1}$ higher than that during the second flood period. The average CPI values of non-urban and urban waters during the first flood period were 53.8 and $65.3 \%$ higher than the second one, respectively. BOD in S4 during the first flood was approximately 2.5 times higher compared with that during the second flood period. As mentioned above, the second flood occurred in 2012 had stronger rainfall intensity and duration than first flood occurred in 2011. After long drought duration in Beijing, soils and sediment enriched lots of pollutants, the first flood event flushed these pollutants from land into the aquatic environment and/or disturbed the sediment, resulting in enhanced pollutant concentrations in the surface water. While, during the second flood period, the former flood had brought most of the pollutants in soils into the aquatic environment; thus, the dilution effect was predominant. In addition, three sampling sites including R1, R2, and S3 showed contrast response (Figure 4), COD values of which during the first flood were lower than those during the second one. This is probably due to the different land use types or pollutant origins such as anthropogenic discharge.

Compared with the first flood period, TP concentrations of most sites exhibited lower concentrations during the second flood period. However, TN concentrations were higher in most non-urban waters during the second flood than those in the first flood. The difference might be caused by that nitrogen compounds were widely used in non-urban areas. Even though large quantity of nitrogen contents was brought by the first flood, there still high contents existing in the soils. In addition, the strong rainfall intensity and duration might disturb the sediments, leading to the release of nitrogen to the surface water. While in most urban lakes, TN concentration showed low concentrations during the second flood period. Although the absolute concentrations of pollutants were low during the second flood period, the large volume of the water discharge contributed large proportion of nutrient loads into the receiving water (Figure S5).

\subsection{Implications for the Impact of Climate Change on Wa- ter Quality}

The surface water quality during the heavy rainfall events is highly dependent on the rainfall intensity and duration, antecedent dry period, pollutant types as well as land use types. According to our previous studies (Wu et al., 2014a, b), there is an increasing trend of heavy rainfall frequency during the past 60 years in Beijing. In addition, temperature in China will enhance by $0.9 \sim 6.1^{\circ} \mathrm{C}$ by 2100 under different climate change scenarios (Liu et al., 2014). The most recent climate change projections about the annual maximum precipitation for 7 days in Haihe River Basin will increase by about $20 \sim 25 \%$ (Yin et al., 2016). Therefore, in the future of increased heavy rainfall events and high temperature, the water quality of both urban and non-urban areas is facing challenges.

Climate change disturbs surface water system including both water quantity and water quality. Therefore, water resource management under climate change based solely on how to defend against the changes of flow during extreme weather events is not enough. Our results suggest that different land use types, hydrological conditions, and pollutant types can result in different response of water quality. Post-drought flushing also contributes to the different variation in water quality during the flood periods. For regions with different characteristics, different flood management strategies should be put forward. For instance, we need establish the immediate-response system for urban water environment during floods due to the imperviousness of land in urban area. In addition, when assessing and building the adaption strategy of water resource to flood and drought, we should consider not only the individual flood but also long-term variations in meteorological factors and regional pollution sources. Moreover, the influence of extreme weather events such as flood on water quality can be alleviated from the source by reducing the point and non-point source pollution. This study results are helpful in establishing the water quality assessment during the flood events of urban and non-urban areas, and also provide basic information for water conservation strategy during the flood periods

\subsection{Future Studies on the Impact of Extreme Weather Events on Water Quality}

Regarding to the increased frequencies and intensities of floods, droughts and high temperature associated with climate change, future studies on impact of extreme weather events on water quality should focus on the influencing mechanisms, applicable assessing methods, data achievement approaches, and water catchment regulations including both surface and ground water. In general, the flood, drought and high temperature affect water quality through affecting the transformation and migration of pollutants. However, the integrated understanding of how do these extreme weather events (i.e., changed water flows, water levels, water residence time, scouring intensity, temperature, and etc.) alter the biogeochemical reactions are still less known. Assessing the extreme weather events especially floods on water quality have no consistent index, some research uses the altered index such as quality indicator (QI) 
and water quality index (WQI) to assess the water quality (Lobato et al., 2015), and some studies assess the influences by measuring the water flows, DOC and DO concentrations (Whitworth et al., 2012; Fink et al., 2016). More realistic and practical assessing methods should be constructed to evaluate the influence of extreme weather events on water quality. In addition, due to the difficulty in achieving the data of water quantity and quality during extreme weather events, more advanced techniques such as remote sensing and online monitoring tools should be adopted into the catchment scale study. Meanwhile, we should also build and improve the current basic database including daily/weekly water quality data, water flows, water levels, aquatic biomass etc. for future projection work. In addition to the macro-scale and mesoscale studies, more field and laboratory work should be conducted to analyze the influence of extreme weather events on biogeochemical reactions in different water bodies (such as shallow/deep lakes, rivers, lagoons, and oceans). Combing the results with fields of micro-biology, hydrology, and etc. can provide a holistic view to pollution prevention and control with global climate change.

Acknowledgements: This work was supported by the National Key R\&D Program of China (2017YFA0605001), National Natural Science Foundation of China (91547207), and the Fund for Innovative Research Group of the National Natural Science Foundation of China (51721093).

\section{References}

Aherne, J., Larssen, T., Cosby, B.J., and Dillon, P.J. (2006). Climate variability and forecasting surface water recovery from acidification: Modelling drought-induced sulphate release from wetlands. Science of the Total Environment, 365(1), 186-199. https://doi.org/10.1016/j. scitotenv.2006.02.041

Beaver, J.R., Jensen, D.E., Casamatta, D.A., Tausz, C.E., Scotese, K.C., Buccier, K.M., Teacher, C.E., Rosati, T.C., Minerovic, A.D., and Renicker, T.R. (2013). Response of phytoplankton and zooplankton communities in six reservoirs of the middle Missouri River (USA) to drought conditions and a major flood event. Hydrobiologia, 705, 173-189. https://doi.org/10.1007/s10750-012-1397-1

Beniston, M. (2012). Impacts of climatic change on water and associated economic activities in the Swiss Alps. Journal of Hydrology, 412, 291-296. https://doi.org/10.1016/j.jhydrol.2010.06. 046

Cann, K.F., Thomas, D.R., Salmon, R.L., Wyn-Jones, A.P., and Kay, D. (2013). Extreme water-related weather events and waterborne disease. Epidemiology \& Infection, 141(04), 671-686. https://doi. org/10.1017/S0950268812001653

Chang, F.J., Tsai, Y.H., Chen, P.A., Coynel, A., and Vachaud, G. (2015). Modeling water quality in an urban river using hydrological factors - Data driven approaches. Journal of Environmental Management, 151, 87-96. https://doi.org/10.1016/j.jenvman.2014. 12.014

Chen, D., Huang, H., Hu, M., and Dahlgren, R.A. (2014). Influence of lag effect, soil release, and climate change on watershed anthropogenic nitrogen inputs and riverine export dynamics. Environmental Science \& Technology, 48(10), 5683-5690. https://doi.org/10. 1021/es500127t

Chen, L., Chen, S., Li, S., and Shen, Z. (2019). Temporal and spatial scaling effects of parameter sensitivity in relation to non-point source pollution simulation. Journal of Hydrology, 571, 36-49. https: //doi.org/10.1016/j.jhydrol.2019.01.045

Delpla, I. and Rodriguez, M.J. (2014). Effects of future climate and land use scenarios on riverine source water quality. Science of the Total Environment, 493, 1014-1024. https://doi. org/10.1016/j.scito tenv.2014.06.087

Dotto, C.B.S., Kleidorfer, M., Deletic, A., Fletcher, T.D., McCarthy, D.T., and Rauch, W. (2010). Stormwater quality models: performance and sensitivity analysis. Water Science \& Technology, 62(4), 837-843. https://doi.org/10.2166/wst.2010. 325

Dotto, C.B.S., Mannina, G., Kleidorfer, M., Vezzaro, L., Henrichs, M., McCarthy, D.T., Freni, G., Rauch, W., and Deletic, A. (2012). Comparison of different uncertainty techniques in urban stormwater quantity and quality modelling. Water Research, 46(8), 2545-2558. https://doi.org/10.1016/j.watres. 2012.02.009

Fink, G., Wessels, M., and Wüest, A. (2016). Flood frequency matters: Why climate change degrades deep-water quality of peri-alpine lakes. Journal of Hydrology, 540, 457-468. https://doi.org/10.1016/ j.jhydrol.2016.06.023

Gallo, E.L., Lohse, K.A., Brooks, P.D., Mclntosh, J.C., Meixner, T., and McLain, J.E.T. (2012). Quantifying the effects of stream channels on storm water quality in a semi-arid urban environment. Journal of Hydrology, 470, 98-110. https://doi.org/10.1016/j.jhy drol.2012.08.047

Gao, Y., Zhu, B., Wang, T., and Wang, Y. (2012). Seasonal change of non-point source pollution-induced bioavailable phosphorus loss: a case study of Southwestern China. Journal of Hydrology, 420, 373379. https://doi.org/10.1016/j.jhydrol. 20 11.12.029

Hamilton, S.K. (2012). Biogeochemical time lags may delay responses of streams to ecological restoration. Freshwater Biology, 57(s1), 4357. https://doi.org/10.1111/j.1365-2427. 2011.02685.x

Heimann, L., Roelcke, M., Hou, Y., Ostermann, A., Ma, W., and Nieder, R., (2015). Nutrients and pollutants in agricultural soils in the peri-urban region of Beijing: Status and recommendations. Agriculture, Ecosystems \& Environment, 209, 74-88. https://doi.org/10. 1016 /j.agee.2015.03.026

Hu, M., Liu, Y., Wang, J., Dahlgren, R.A., and Chen, D. (2018). A modification of the Regional Nutrient Management model (ReNuMa) to identify long-term changes in riverine nitrogen sources. Journal of hydrology, 561, 31-42. https://doi.org/10.1016/j.jhydrol.2018.03. 068

Hubbard, L., Kolpin, D.W., Kalkhoff, S.J., and Robertson, D.M. (2011). Nutrient and sediment concentrations and corresponding loads during the historic June 2008 flooding in eastern Iowa. Journal of Environmental Quality, 40(1), 166-175. https://doi.org/ $10.2134 /$ jeq2010.0257

Hrdinka, T., Novický, O., Hanslík, E., and Rieder, M. (2012). Possible impacts of floods and droughts on water quality. Journal of Hydroenvironment Research, 6(2), 145-150. https://doi.org/10.1016/j.jher. 2012.01.008

Kjeldsen, T.R., Miller, J.D., and Packman, J.C. (2013). Modelling design flood hydrographs in catchments with mixed urban and rural land cover. Hydrology Research, 44(6), 1040-1057. https://doi.org/ $10.2166 / \mathrm{nh} .2013 .158$

Li, J.K., Li, H., Shen, B., and Li, Y.J. (2011). Effect of non-point source pollution on water quality of the Weihe River. International Journal of Sediment Research. 26(1), 50-61. https://doi.org/10.10 16/S10016279(11)60075-9

Launay, M., Dittmer, D., Steinmetz, H., and Kuch, B. (2013). Temporal variations of organic pollutants levels during storm events in an urban receiving water body. In Proc. of 8th NOVATECH International Conference on Sustainable Techniques and Strategies in Urban Water Management, Lyon, France, 23rd 27th June.

León, V.M., Moreno-González, R., García, V., and Campillo, J.A. (2015). Impact of flash flood events on the distribution of organic pollutants in surface sediments from a Mediterranean coastal lagoon (Mar Menor, SE Spain). Environmental Science and Pollution Research, 24(5), 4284-4300. https://doi.org/10.1007/s 11356-0154628-y

Liu, S., Lou, S., Kuang, C., Huang, W., Chen, W., Zhang, J., and Zhong, 
G. (2011). Water quality assessment by pollution-index method in the coastal waters of Hebei Province in western Bohai Sea, China. Marine Pollution Bulletin, 62(10), 2220-2229. https://doi.org/10. 1016 /j.marpolbul.2011.06.021

Liu, Y., Feng, J., and Ma, Z. (2014). An analysis of historical and future temperature fluctuations over China based on CMIP5 simulations. Advances in Atmospheric Sciences, 31(2), 457-467. https://doi.org/ 10.1007/s00376-013-3093-0

Liu, R., Xu, F., Zhang, P., Yu, W., and Men, C. (2016). Identifying nonpoint source critical source areas based on multi-factors at a basin scale with SWAT. Journal of Hydrology, 533, 379-388. https://doi. org/10.1016/j.jhydrol.20 15.12.024

Lobato, T.C., Hauser-Davis, R.A., Oliveira, T.F., Silveira, A.M., Silva, H.A.N., Tavares, M.R.M., and Saraiva, A.C.F. (2015). Construction of a novel water quality index and quality indicator for reservoir water quality evaluation: A case study in the Amazon region. Journal of hydrology, 522, 674-683. https://doi.org/10.1016/j.jhy drol.2015.01.021

Madarang, K.J., and Kang, J.H. (2014). Evaluation of accuracy of linear regression models in predicting urban stormwater discharge characteristics. Journal of Environmental Sciences. 26(6), 13131320. https://doi.org/10.1016/S1001-0742(13)606 05-1

McCarthy, B., Zukowski, S., Whiterod, N., Vilizzi, L., Beesley, L., and King, A. (2014). Hypoxic blackwater event severely impacts Murray crayfish (Euastacus armatus) populations in the Murray River, Australia. Austral Ecology, 39(5), 491-500. https://doi.org/10.1111/ aec. 12109

Mosley, L.M. (2015). Drought impacts on the water quality of freshwater systems; review and integration. Earth-Science Reviews, 140, 203-214. https://doi.org/10.1016/j.earscirev.201 4.11.010

Özen, A., Karapınar, B., Kucuk, I., Jeppesen, E., and Beklioglu, M. (2010). Drought-induced changes in nutrient concentrations and retention in two shallow Mediterranean lakes subjected to different degrees of management. Hydrobiologia. 646(1), 61-72. doi:10.1007 /s10750-010-0179-x.

Putro, B., Kjeldsen, T.R., Hutchins, M.G., and Miller, J. (2016). An empirical investigation of climate and land-use effects on water quantity and quality in two urbanising catchments in the southern United Kingdom. Science of the Total Environment, 548, 164-172. https://doi.org/10.1016/j.scitotenv.2015.12.132

Ramachandran, A., Krishnamurthy, R.R., Jayaprakash, M., and Shanmugasundharam, A. (2018). Environmental impact assessment of surface water and groundwater quality due to flood hazard in Adyar River Bank, Acta Ecologica Sinica, In press. https://doi.org/10.1016 /j.chnaes.2018.08.008

Stott, P.A., Christidis, N., Otto, F.E., Sun, Y., Vanderlinden, J.P., Van Oldenborgh, G.J., Vautard, R., Von Storch, H., Walton, P., Yiou, P., and Zwiers, F.W. (2016). Attribution of extreme weather and climate-related events. Wiley Interdisciplinary Reviews: Climate Change, 7(1), 23-41. https://doi.org/10.10 02/wcc.380

Ummenhofer, C.C., and Meehl, G.A. (2017). Extreme weather and climate events with ecological relevance: a review. Philosophical Transactions of the Royal Society B: Biological Sciences, 372(1723), 20160135. https://doi.org/10.1098/rstb. 2016.0135

Van Meter, K.J., and Basu, N.B. (2017). Time lags in watershed-scale nutrient transport: an exploration of dominant controls. Environmental Research Letters, 12(8), 084017. https://doi.org/10.1088/ 1748-9326/aa7bf4

Van Vliet, M.T.H., and Zwolsman, J.J.G. (2008). Impact of summer droughts on the water quality of the Meuse river. Journal of Hydrology, 353(1), 1-17. https://doi.org/10.1016/j.jhydrol.2008.01. 001

Vincent, J., and Kirkwood, A.E. (2014). Variability of water quality, metals and phytoplankton community structure in urban stormwater ponds along a vegetation gradient. Urban Ecosystem, 17(3), 839-853. https://doi.org/10.1007/s11252-01 4-0356-1

Walling, D.E., and Foster, I.D.L. (1975). Variations in the natural chemical concentration of river water during flood flows, and the lag effect: some further comments. Journal of Hydrology, 26(3-4), 237-244. https://doi.org/10.1016/0022-1694(75)9000 5-0

Whitworth, K.L., Baldwin, D.S., and Kerr, J.L. (2012). Drought, floods and water quality: drivers of a severe hypoxic blackwater event in a major river system (the southern Murray of eing Basin, Australia). Journal of Hydrology, 450, 190-198. https://doi.org/10. 1016 /j.jhydrol.2012.04.057

Wu, Q., Xia, X.H., Li, X.H., and Mou, X.L. (2014a). Impacts of meteorological variations on urban lake water quality: a sensitivity analysis for 12 urban lakes with different trophic states. Aquatic Sciences, 76(3), 339-351. https://doi.org/10.1007/s00027-014-033 $9-6$

Wu, Q., Xia, X.H., Mou, X.L., Zhu, B.T., Zhao, P.J., and Dong, H.Y. (2014b). Effects of seasonal climatic variability on several toxic contaminants in urban lakes: Implications for the impacts of climate change. Journal of Environmental Sciences, 26(12), 2369-2378. https://doi.org/10.1016/j.jes.2014.04.001

Wang, D., Cossitt, K., and Dormuth, D.A. (2008). Comprehensive water quality monitoring in urban stormwater detention ponds. National Research Council of Canada Publication No. NRCC50589, National Research Council of Canada, Ottawa, Ontario

Xia, X.H., Zhao, X.L., Lai, Y.J., and Dong, H.Y. (2013). Levels and distribution of total nitrogen and total phosphorous in urban soils of Beijing, China. Environmental Earth Sciences, 69(5), 1571- 1577. https://doi.org/10.1007/s12665-012-1991-6

Xia, X.H., Wu, Q., Mou, X.L., and Lai, Y.J. (2015a). Potential impacts of climate change on the water quality of different water bodies. Journal of Environmental Informatics, 25(2), 85-98. https://doi.org/ 10.3808/jei.201400263

Xia, X.H., Wu, Q., Zhu, B.T., Zhao, P.J., Zhang, S.W., and Yang, L.Y. (2015b). Analyzing the contribution of climate change to long-term variations in sediment nitrogen sources for reservoirs/lakes. Science of the Total Environment, 523(1), 64-73. https://doi.org/10.1016 /j.scitotenv.2015.03.140

Yin, J., Yan, D., Yang, Z., Yuan, Z., Yuan, Y., and Zhang, C. (2016). Projection of extreme precipitation in the context of climate change in Huang-Huai-Hai region, China. Journal of Earth System Science, 125(2), 417-429. https://doi.org/10.1007/s00704-014-11 59-2

Yuan, Z.W., Wang, L., Lan, T., Ji, Y., and Zhao, H.Z. (2016). Water quality assessment and source identification of water pollution in the Banchengzi reservoir, Beijing, China. Desalination and Water Treatment, 57(60), 29240-29253. https://doi.org/10.1080/194439 94.2016.1162205 